\title{
CONTACTO INTERÉTNICO EN EL NORTE DE TIERRA DE FUEGO: PRIMERA APROXIMACIÓN A LAS ESTRATEGIAS DE RESISTENCIA SELK'NAM
}

CASALI, ROMINA

\section{RESUMEN}

Se plantea una discusión acerca de las posibilidades y/o capacidades de elaborar una estrategia de resistencia ante la colonización por parte de los Selk'nam, hacia fines del siglo XIX. Se analizaron fuentes primarias (consultadas en el archivo del Museo del Fin del Mundo, Ushuaia, Tierra del Fuego) etnográficas, históricas y etnohistóricas, a fin de proponer una primera aproximación a la problemática. Se sugiere un esquema de resistencia considerando variables concernientes tanto a los dispositivos de poder, como también a la agencia del conquistado, examinándose el determinismo de las formas de la colonización ante las potenciales respuestas de los aborígenes.

PALABRAS CLAVE: Contacto interétnico, Selk'nam, resistencia, dispositivos de poder.

\section{INTERETHNICAL CONTACTS IN THE NORTH OF TIERRA DEL FUEGO: FIRST APPROACH TO THE SELK'NAM RESISTANCE STRATEGY}

\begin{abstract}
This paper presents a discussion about the possibilities and / or capabilities to develop a strategy of resistance to colonisation by the Selk'nam, towards the end of the nineteenth century. We analyzed primary sources (consulted on file with the Museo del Fin del Mundo, Ushuaia, Tierra del Fuego) ethnographic, historical and etnohistorical, to propose a first approach to the problem. It suggests a pattern of resistance considering variables concerning both the power devices, as well as the agency of the conquered. It also examines the determinism of the forms of colonization to the potential responses of Aborigines.
\end{abstract}

KEY WORDS: Interethnic contact, Selk'nam, resistance, power devices.

\footnotetext{
Becaria FONCYT, Proyecto 06-1520. Lab. de Ecología Evolutiva Humana, UNCPBA. Calle 508 № 881 (entre 517 y 521 ) CP 7631. Quequén -Distrito Necochea- Pcia. Buenos Aires. Argentina. Tel: 02262- 450707. Tel/Fax:02262- 451041. rcasali@mdp.edu.ar
} 
El presente trabajo se enmarca en un proyecto más amplio referido al contacto interétnico en el norte de Tierra del Fuego y aborda una de las tantas facetas que encuadra dicho proceso, en este caso particular las consecuencias suscitadas en los Selk'nam -pobladores originarios que ocuparon el interior de la isla como cazadores-recolectores-, en función de la actitud adoptada ante la presencia de la sociedad cristiana. Se intentará rastrear en distintas fuentes primarias, etnográficas, etnohistóricas e históricas las respuestas ofrecidas por los Selk'nam ante el proceso de constitución estatal en el extremo patagónico-fueguino de los actuales territorios argentino-chileno. El objetivo es efectuar una estimación, proponer al menos una discusión, acerca de la posibilidad y/o la capacidad / voluntad de elaboración de una estrategia de resistencia por parte de los Selk'nam, teniendo en cuenta los diversos dispositivos de poder, pero también los valores, costumbres, características y formas de la cultura aborigen, aunque éstas estén cernidas por la perspectiva del observador, integrante de la cultura conquistadora.

Se sistematiza la información en forma tal de que oficie de una primera aproximación a la problemática, lo mismo que de contexto al análisis paralelo que se realizó de las fuentes primarias correspondientes a la Misión Salesiana La Candelaria, Río Grande (Casali y Guichón 2008, MS), lugar en el que residieron aborígenes Selk'nam a medida que su territorio era irrumpido a causa de la actividad ganadera ovina.

Redunda mencionar que en los últimos años, desde la historia como disciplina, acudimos a planteos de relaciones bidireccionales -con diverso grado de intensidad y probabilidad según el caso-, ya que el estudio del contacto interétnico ha incluido una visión dónde los grupos indígenas aparecen como agentes activos de ese proceso diseñando sus propias estrategias para resistir, confrontar y/o incorporarse de la mejor manera posible en las nuevas estructuras estatales que comienzan a gestarse a fines del siglo XIX (Ratto 2007: Introducción). Pretendemos aportar a estos postulados, mediante un estudio de caso aún no tratado desde esta perspectiva. Descartamos el determinismo analítico, ya sea de la paridad absoluta de las unidades étnicas en función de su posibilidad de acción, ya sea del absolutismo de la estructura social respecto del maniobrar de la etnia subordinada.

\section{MARCO HISTÓRICO}

Ya se ha escrito acerca de que los Selk'nam (Onas) ocuparon el interior de la isla Grande, como cazadores- recolectores dedicados al aprovechamiento de guanacos, pero también de recursos marinos, frutos, vegetales, aves, entre otros. También es sabido que Tierra del Fuego comenzó a ser colonizada hacia 1850 desde el sur con los intentos de los anglicanos por establecer una misión, lo cuál se efectivizó en 1870 en la actual Ushuaia. Su principal impulsor, el reverendo Thomas Bridges, decidió concluir su tarea religiosa a partir de las consecuencias demográficas en los Yámana de las epidemias dadas en la región, partiendo hacia las 20.000 hectáreas cedidas por el gobierno nacional para que realizara tareas ganaderas (Bridges 2008:138). El contacto de la familia Bridges con los Selk'nam fue intenso, impuesto por la convivencia y el trato diario. Especialmente, a partir de que Lucas y Guillermo instalaran la estancia Viamonte en 1907, en pleno territorio Selk'nam, siendo parte fundamental en la tarea predicadora que los salesianos impulsaran por toda la isla desde 1910, mediante el mecanismo de misiones volantes. Los hijos Bridges se contactaron desde jóvenes con los Selk'nam, formaron parte en sus ceremonias y mantuvieron un vínculo paternalista dentro de sus estancias que no excluía su aprovechamiento como mano de obra.

Precedida por las exploraciones decimonónicas, propias de la constitución de los estado-nación, comenzó la explotación de las potencialidades económicas de la isla. Primero fueron los placeres auríferos (1881 en el sector chileno) y aunque no llegaron a saciar las expectativas que su descubrimiento había generado, en torno a éstos se suscitaron los primeros hechos de violencia, importantes no por su incidencia cuantitativa sobre los Selk'nam, sino por sus efectos a nivel psicológico y cultural. La organización de la actividad trajo aparejada la llegada de distintos pobladores, trabajadores y proveedores (Borrero 2001:62) y la irrupción de los mineros conllevó un contacto de tipo violento y fue en estas circunstancias que el indígena fueguino comenzó a conocer al hombre blanco que poco a poco iba invadiendo su territorio y asentándose en él, trato que iba dejando como lamentable fruto resentimientos, vejaciones, enfermedades $y$ muertes (Martinic 1982: 48). 
En 1886, uno de los más conocidos conquistadores de la isla, el ingeniero rumano Julio Popper, comenzó a extraer oro en el extremo norte de la bahía San Sebastián (Argentina), en un escenario en el que el estado no había aún consolidado su autoridad. La celebridad de Popper radica en las diferentes aristas de su despotismo, sea la violencia contra los aborígenes o el enfrentamiento con los gobernadores, hasta la acuñación de moneda y estampillas postales como símbolo de su dominio sobre el lugar (Bandieri 2005: 189). En 1884 el gobierno argentino instaló la subprefectura en Ushuaia y encomendó expediciones que permitieran el conocimiento de la región para su posterior explotación económica. Tal fue el caso de la incursión dirigida en 1886 por Ramón Lista (funcionario del Ministerio de Guerra y Marina de Argentina), medio de uno de los primeros hechos de sangre en la isla, en el que perdieron la vida 28 Selk'nam (De Agostini 1956: 286).

En 1885, desde el sector chileno, se efectivizaron las primeras concesiones de tierras. La cría de ganado ovino, en función de las demandas del mercado internacional y de las potencialidades productivas de la región, habría constituido el factor primordial en la desaparición de la etnia Selk'nam. Existieron consecuencias tanto directas como indirectas. Entre las primeras se hallaba la matanza por parte de los propietarios de tierras, los administradores de las estancias o los empleados. Las segundas surgieron fundamentalmente a partir del cercado de los territorios, ya que el desplazamiento de los aborígenes entrañó una alteración en su territorialidad y el consecuente enfrentamiento intraétnico o la potenciación del ya existente. La competencia y desplazamiento del guanaco, recurso básico de los Selk'nam, por parte de las ovejas, habría implicado por un lado la escasez de alimento y otras materias primas $y$, por el otro, que los aborígenes fueran capturados o asesinados por intentar aprovechar a las ovejas como nueva fuente nutricional.

Fue en el marco de los intereses de los propietarios ganaderos de poder llevar adelante sus tareas productivas sin mayores alteraciones, que las autoridades chilenas percibieron lo oportuno de acceder a las intenciones de los misioneros salesianos de salvaguardar la cultura Selk'nam. Monseñor Fagnano, integrante de la misión de Lista, testigo entonces de aquel premonitorio suceso de violencia, se convirtió en el promotor de la estrategia de trasladar a los Selk'nam a la misión salesiana que en 1889 comenzó a construirse en la isla Dawson. Así, la maniobra tomó forma de deportaciones, las cuáles habrían ascendido a 800 durante los años de funcionamiento de dicha misión, 1889-1911 (Martinic 1973). Sólo entre 1892 y 1895, por ejemplo, se trasladaron más de 380 Selk'nam (Braun Menéndez 1939), lo que coincide con la instalación a partir de 1893 de la Sociedad Explotadora de Tierra del Fuego, propiedad de Sara y Mauricio Braun. Ésta ocupó la totalidad de la enorme porción de territorio que le correspondía y que era en el hecho el corazón del país ona (Martinic 1973). La empresa estaba decidida a invertir grandes capitales en la explotación pastoril y a defender su patrimonio, por lo que se preparó para repeler con eficacia a los indígenas y cómo primera y práctica medida se incluyeron entre los empleados contratados para iniciar la explotación, aquellos cuya única finalidad era la de vigilar a los onas (Martinic 1973). La fundación oficial del primer poblado fueguino, Porvenir, sobrevino en 1894 y en 1896 se estableció la primera guardia policial permanente.

Hacia mediados de los noventa, la labor ganadera daría inicio también en tierras argentinas, coincidentemente con la instalación de otra misión salesiana. Nuestra Señora de La Candelaria (1893) se erigió definitivamente tras el incendio de diciembre de 1896 a 14 kilómetros de la actual ciudad de Río Grande y hasta 1928 persistió en sus funciones de Misión evangelizadora.

\section{MARCO TEÓRICO - METODOLÓGICO}

Para eludir la sensación de precariedad que podría denotar una simple sumatoria de citas de sucesos y manifestaciones discursivas, es conveniente que un trabajo dialogue con modelos teóricos, indispensables para la continuidad de la tarea intelectual, su regeneración y permanencia. Claro que los paradigmas asocian rigidez con flexibilidad nimia, por lo que vale evitar su adopción en forma de esquema acabado y extrapolable y atender a los matices y alteraciones que incluyen las realidades específicas. La dialéctica es constante y es parte del desafío de generar convocatorias eruditas: cabe un análogo esfuerzo por intentar responder a ellas, sin omitir que la mera actividad docta podría carecer de significación social. Las tesis serán vertidas entonces 
como referentes, dejando al margen un exhaustivo análisis de cada una, tarea que excede a los objetivos de este trabajo. Igual razón fundamenta la exclusión de tantas otras potenciales tipologías.

No está de más postular la guía setentista de Cardoso de Oliveira como punto de partida. Aunque ya vetusto según los años transcurridos, su actualidad teórica permite incluir la experiencia Selk'nam en una situación de fricción interétnica, signada por la relación entre grupos tribales y segmentos regionales de la sociedad nacional (Cardoso de Oliveira 1988:285) en situación de asimetría. Un tipo de vínculo entendible desde las categorías de subordinación-dominación, regido por rasgos conflictivos surgidos de la supremacía políticaeconómica-militar del grupo no aborigen. Cardoso propone a la etnicidad como correlato, en el plano superestructural, de las situaciones estructurales de dominación que constituyen la fricción interétnica: una autodefinición como alternativa a la alienación que, producto de la realidad, intenta alejarse de ella y hasta revertirla en algunos casos (idem: 298). En otros, la solución misma puede resultar enajenante, cuando se construye una ideología de la sumisión, donde priman las representaciones que el blanco transfirió a los indígenas a partir de su dominación. El aborigen legitima así el status quo del sistema interétnico abdicando de cualquier movimiento social de transformación de sus condiciones de vida (idem: 299), afirmando la desigualdad étnica, relegando a sus portadores a la inferioridad. En este último plano es donde nace la tentación de ajustar la cuestión Selk'nam. Claro que discernir los límites entre las órbitas del voluntarismo y el determinismo estructural no puede más que invitar a exámenes que no excluyan ninguna de las agencias, ni la del conquistador, ni la del conquistado, como se anticipara en la introducción.

También para Martha Bechis la etnicidad -más aún, la etnia- surge en un contexto de contacto $y$ distinción entre el grupo mío o comunidad mía y los grupos otros o las otras comunidades (Bechis 2005: 8). Ocurriría una forma de autoconciencia en función del otro -y a partir del otro-, un modo de expresar ideológica o culturalmente una situación que ostenta un origen en la exclusión mutua de intereses contrapuestos en la esfera político económica. Aquí, la instancia analítica distintiva sería, atender a una forma bidireccional, a una interacción más compleja entre las fases, en la que se perciba una cierta dinámica que no necesariamente implique un etno exclusivamente reactivo. Si $A$ afecta a $B$ y $B$ levanta defensas contra esas influencias, es porque en un mínimo sentido $B$ afecta a $A$ (idem: 4). A fin de no incurrir en la trampa de la aculturación, la autora minimiza la unilinealidad entre el centro y la periferia y propone rastrear también la posible presencia en los etnos de alguna acción de resistencia a esas influencias. Incorporando los postulados diversos que confluyen en la psicología social, esgrime un cierto equilibrio entre la concepción del vínculo interétnico como producto histórico $-y$ la potencial presencia de asimetría entre las partes involucradas- y una igualdad de condiciones entre los segmentos, en su posición de partícipes y de sujetos modificados a partir de la interacción.

Huelga acotar que Boccara desvanece los límites entre la etnicidad y la etnogénesis al hablar de la apropiación del otro en momentos de definición del self (Boccara 2001). Para el caso Selk'nam podría hablarse de una combinación entre dispositivos de poder soberanos y disciplinarios, ya que las expediciones militares corrieron paralelas al establecimiento de las misiones salesianas, interdependientes. Técnicas polimorfas de sometimiento, en las que el dominio denotaba represión y creatividad, forma combativa y política: normalizar, contabilizar, civilizar (Boccara 1996). Proponemos que, contrariamente a lo ocurrido en el caso reche/mapuche, los Selk'nam no lograron mutar positivamente -permítasenos la valoración-a partir de las variables jerarquía/ territorio. No generaron resistencia mediante la estructuración de una diferenciación social que permitiera la aparición de un linaje capaz de negociar política y económicamente. La estructura social habría sido determinante llegado el momento de impulsar alguna forma de resistencia a través de la territorialización: los Selk'nam no sólo no pudieron expandirse y operar en un marco regional, sino que -obviamente- se vieron repelidos a espacios más pequeños.

La tierra y su significación económica; el territorio y sus acepciones socio culturales: la desterritorialización habría sido concluyente para el caso Selk'nam, reemplazando tensión interétnica por exclusión, en tanto la existencia de las dos unidades étnicas resultaba incompatible. Las relaciones sociales respondieron a la estatalización inherente al sujeto que subordinaba, normaba y pautaba en 
tanto expresión de mecanismos económicos (Correa 2004: 7). Los Selk'nam asistieron a su conquista por parte de los estados argentino y chileno que, aunque no en forma coordinada desde las instancias gubernamentales, sí configuraron la realidad fueguina legitimando las consecuencias directas e indirectas que la producción pecuaria tenía sobre la integridad material, física y cultural de los aborígenes.

Tal como se desprende del marco histórico, persecución, asesinatos, deportaciones a la misión en Dawson, traslados a Punta Arenas -incluido un remate de indígenas por parte del Gobernador chileno, Señoret- (Aliaga Rojas 1984: 43), repartimiento como mano de obra en la ciudad y en las estancias, instalación de la Misión en Río Grande, propagación de actividades productivas, como la explotación aurífera, pero sobre todo el afincamiento de estancias, constituyeron dispositivos de poder. Para algunos autores, también debería incluirse en la esfera de la acción estatal elementos tales como las epidemias, los cambios en el medio físico por la introducción de nuevas plantas, animales o tecnología (Ratto 2007: Introducción).

Ahora bien, quiénes eran los Selk'nam. Desde la perspectiva antropológica, abundan los estudios acerca de esta comunidad y claramente no pretendemos aquí emular siquiera un renglón de lo ya escrito. Sencillamente, ensayamos abordar desde la mirada de la historia, algunas de las peculiaridades de la comunidad que ofrecen las fuentes y que podrían contribuir al entendimiento de la agencia Selk'nam en tanto su comportamiento frente al conquistador. Tal ejercicio no debe ser homologado con una cosificación/esencialización de su cultura o con la naturalización de sus respuestas. Sería como adherir a la desusada dicotomía antropología versus historia, considerando que una mirada antropológica es incompatible con la historicidad de las relaciones.

\section{CITAS RELEVANTES PARA EL ESTUDIO DE LA RESISTENCIA ENTRE LOS SELK'NAM}

Vale mencionar que no se aclarará en cada cita cuáles de los conceptos vertidos y en que grado son propios de enjuiciar por su pertenencia a un discurso dominante, representante de la civilización, la ciencia, el estado o la religión, ya que sería una obviedad. Lo mismo podría argüirse en función de la posición social y de los intereses y objetivos para con los Selk'nam, por parte de cada uno de los oradores. Es preciso aclarar que a fin de no importunar la lectura, a continuación se harán explícitas sólo algunas de las citas adecuadas para graficar los aspectos escogidos.

Respecto a la docilidad Selk'nam

Los ona han sido gente de buena índole, y si se les ofreciera una buena oportunidad probarían que son dignos del nombre, ritos y privilegios de hombres. Pero tal oportunidad no se les presenta. Antes que tomarse ninguna molestia respecto de ellos, son mantenidos por medio del rifle lo más lejos posible (Bridges 1886:204).

El sacerdote salesiano Antonio Coiazzi compara el carácter de los Selk'nam con los Kawéskar. Dice que el representante de los primeros, Eliseo, está siempre alegre, jovial y de buen humor (...) en general, los alacalufes son tristes y taciturnos; los onas, al contrario, son más joviales y expansivos. Los alacalufes, además de ser taciturnos y tristes son traicioneros, lo que parece consecuencia o causa de su carácter cerrado (Coiazzi 1997:15).

A continuación, Coiazzi menciona un hecho de rebeldía, por demás conocido y relatado, por parte de Kawéskar que intentaron asesinar a los curas de la Misión San Rafael (Dawson), en septiembre de 1889, valiéndose de la oportunidad para nuevamente signar disparidades entre ambas etnias.

Los onas poseen bondad de corazón hacia los bienhechores, hospitalidad, docilidad en seguir los consejos, dulzura de carácter para con quien los trata bien, deseo de elevarse a nuestra cultura, sobre todo en cuestión de religión y moral. Evidentemente todas estas energías estaban latentes y casi sofocadas ante la hostilidad de los civilizados explotadores; fue necesaria la caridad del misionero para que manifestasen también al europeo aquellas buenas cualidades que ya se conocían en sus relaciones privadas (Coiazzi, 1997:89)

En general los Onas son muy alegres, siempre sonrientes de una sonrisa simple y confidente, jamás tristes, por lo que inspiran confianza (...) Son muy serviciales (...) y siempre gratuitamente (...) Si no le hubieran hecho el mal o si no hubieran molestado a sus mujeres, no habrían jamás molestado a los blancos (Borgatello, 1921: 70-71). 
Los actos de crueldad y sevicia que se perpetraron contra los indios onas (...) y que tanto ha contribuido a la rápida extinción de una raza inofensiva y vigorosa, pasarán a la posteridad como una mancha vergonzosa de la civilización (De Agostini,1956:287) Para justificar los actos de barbarie efectuados por el blanco (envenenamiento con estricnina, pago de un libra esterlina a cambio de las orejas o la cabeza, matanzas, deportaciones, robo de mujeres y niñas), la fantasía de los civilizados forjó exageradas descripciones de emboscadas, ataques mortíferos por parte de los indios y horribles escenas de matanzas y saqueos, mientras en realidad el indio ona jamás se demostró belicoso sino para tutelar sus bienes, sus tierras y su familia. Nunca fue sanguinario; tan solo cuando vio tomado de mira por los blancos, se vengó por represalia, y a veces terriblemente (idem:288) Infelices indios, oprimidos e incapaces de hacer valer sus derechos (idem:289). Eran siempre joviales y expansivos, razón por la cuál inspiraban confianza y atraían muy pronto la benevolencia de los civilizados (idem:305). De Agostini, misionero salesiano, explorador, fotógrafo y documentalista italiano llegado a la región hacia 1910.

Todas las referencias acumuladas hasta la llegada de los mineros (1881) señalan la índole pacífica de los onas (Martinic 1973:38). M. Martinic, historiador chileno.

Se cometería una grave injusticia con nuestros indígenas si se continuara sosteniendo la afirmación de que consideran indiscriminadamente como enemigo declarado a cualquier europeo, al que tratan de perjudicar con invariable odio. Tales suposiciones son desbaratadas por una referencia a su encuentro amistoso con los antiguos navegantes, a su confianza durante las primeras incursiones de los europeos al interior de la Isla Grande, a su apego a los misioneros y hacendados, y por ultimo a su altruismo hospitalario en favor de tantos individuos (Gusinde 1982: 509). M. Gusinde, sacerdote y etnólogo alemán.

los conocí siempre buenos y si alguna vez se los vio irritados, ello se debió a que algunos de los buscadores de oro o los aventureros que cruzaban la estancia, los trataron mal (Testimonio de Ernesto Hobbs, uno de los directores gerentes de la estancia Gente Grande, Sociedad Anónima Ganadera. Massa 1945: 325) por el contrario, sabemos que los Onas han sido (...) bastante hospitalarios y estoy bien seguro, que si éstos pobres náufragos noruegos en playa fueguina se hubiesen encontrado con los onas, no solo no habrían tenido que sufrir daño alguno, sino que estos compadeciéndose de ellos, los habrían ayudado, socorrido (Beauvoir 1997: 212). J. M. Beauvoir, sacerdote salesiano.

(...) de manera que el indio ese, confiado y bondadoso que salía al encuentro de los expedicionarios para ser cargado y fusilado (Holmberg, E. A. citado en Belza 1974: 315)

(...) los indios onas eran más afables...más tratables y dados al trabajo (testimonio del coadjutor salesiano Máximo Asvini, citado en Belza 1974: 318)

Respecto a la jerarquía y/o división social en la sociedad Selk'nam

Nuestros Selk'nam no conocen ningún tipo de institución permanente de orden público. Carecen tanto de un caudillo general común [cacique], como de jefes sobre varias familias o sobre grupos más o menos grandes. Un hombre maduro debe su posición preferencial, en el ámbito familiar, solo a sus cualidades intelectuales, a sus facultades personales y a sus años. Por tal razón, sólo puede aconsejar o recomendar según su juicio bien intencionado, pero no puede obligar mediante normas legislativas (Gusinde 1982:509).

La organización de los onas como agrupación humana, se muestra como de las más sencillas, es decir, que ella sólo puede considerarse como dando la nota de las más primitivas manifestaciones de la sociabilidad entre los hombres (...) no tienen siquiera un jefe que sirva de representación de autoridad o de núcleo alrededor del cual se agrupen los individuos (Gallardo 1910:207). C. Gallardo, médico argentino.

Están constituidos sobre la base de la más perfecta libertad e igualdad, sistema que trae como consecuencia, en muchos casos, el predominio de la fuerza. Esto no quiere decir que el ona haga lo que quiera; está sujeto a leyes que si bien no están escritas se respetan (...) En la guerra no hay jefes; todos y cada uno deben matar el mayor número posible de enemigos. Como se ve no hay en esto ni siquiera las primeras manifestaciones de un 
sistema de gobierno; sólo se ve el sentimiento de la solidaridad. El médico es el único que tiene una influencia poderosa en la tribu (...) por su ciencia: desaparecida ésta, cesa su poder y sólo queda el respeto, tal vez por temor. Entre los onas se nota, a pesar de lo expuesto, la influencia moral del audaz, del que ha probado ser más prudente, del que tiene más experiencia, pero esta influencia solo dura mientras se realiza el acto en que se necesita la ayuda de aquellas buenas cualidades (Gallardo 1910: 209).

No tienen organización social, ni jefes ni caciques establecidos y están únicamente divididos en grupos de familias según su consaguinidad (Dabbene 1904:71).

No hay entre ellos un jefe que represente la autoridad sobre determinado número de individuos, y el único vínculo social lo constituye la mera agrupación de familias, unidas, comúnmente por los vínculos de parentesco (De Agostini 1956:320). El hombre es el jefe de la familia, al que deben obedecer ciegamente todos sus miembros; la unión de varias familias corresponde únicamente a la recíproca ventaja de la sociabilidad. Esto no obstante, el brujo (Kon) ejerce un notable influjo sobre los componentes de la tribu (ídem: 321).

La sociedad Selk'nam prescindía de jefes, consejo de ancianos u otro órgano de autoridad. Los adultos tenían ascendencia sobre los jóvenes, especialmente durante la ceremonia del hain, pero fuera de esto el ejercicio del poder era más bien circunstancial (Chapman 1998: 67).

no reconocen jefe ni tienen caciques y sólo cuando entran en pelea obedecen a los ancianos que los dirigen. Toda su táctica consiste entonces en desplegarse en guerrillas y vencer o morir (Segers 1891: 61).

Los onas no tenían jefes hereditarios ni electivos, pero los hombres que sobresalían por su habilidad casi siempre se convertían de hecho en dirigentes. Sin embargo, uno podía ser jefe hoy y otro mañana, pues se lo cambiaba según la empresa a acometer y se designaba al más vehemente partidario de cada una (...) sí señor, los onas tenemos muchos jefes: todos los hombres son capitanes y todas las mujeres son marineras (Bridges 2008: 213).

Respecto a la organización social de los Selk'nam y a la posible presencia de algún tipo de jerarquía que pudiera haber sido funcional a la elaboración de estrategias de resistencia, la información brindada por Anne Chapman pareciera correr en el sentido de la carencia de las mismas. Las posiciones sociales con un cierto prestigio se vinculaban más con aspectos religiosos: mitológicos (sabios), proféticos (profetas) y a la capacidad de sanar (chamanes). Los guerreros, los campeones de lucha y los mejores corredores eran honrados con títulos especiales. El guerrero era reconocido por su edad, su experiencia y su conocimiento de la tradición, pero no era un líder moral ni tampoco un anciano respetado (Chapman 1998: 77).

Habilítesenos la oportunidad de inferir de las fuentes, la adjudicación a los Selk'nam de una división social basada en criterios de género y edad, perceptibles en lo cotidiano, pero fundamentalmente en escenas ceremoniales o bélicas. Una muy interesante legitimación de estas consideraciones es efectuada por Dánae Fiore, quien ha demostrado como el uso de pinturas corporales en los Selk'nam, implicaba la creación y manipulación de información visual y mítica, mediante la creación de símbolos que representaban roles (xons) y de verdaderas corporizaciones visibles de espíritus (hain) (...) fuentes de poder de algunas personas sobre otras. Eran mecanismos que generaban divisiones sociales con una base material concreta -no sólo simbólica- en el manejo de recursos materiales (pigmentos, aditivos, recipientes, instrumentos para pintar), sin la necesidad de manipular excedente en la esfera de la subsistencia y/o la tecnología (Fiore 2006).

Respecto a la guerra en la sociedad Selk'nam

Antes de que los civilizados ocupasen sus tierras, estaban animados los onas de fuerte espíritu guerrero, que los arrastraba a sangrientas luchas contra las tribus vecinas. Daban, por lo general, motivo a ellas el rapto de alguna mujer o la invasión de tierras propias o cuando se creía que una enfermedad había sido provocada por el brujo de otra tribu. El indio, habilísimo rastreador, espiaba los movimientos del enemigo, seguía su rastro, lo esperaba oculto durante horas entre las sinuosidades del terreno o en la oscuridad de la floresta, y llegado el momento propicio, atacaba en orden disperso arrojando sus flechas mortales. En estas peleas no tenían un jefe determinado sino que 
obedecían a los más ancianos, que les indicaban los movimientos; toda su táctica consistía en caer de improviso sobre el enemigo, sorprendiéndolo desprevenido y colocándose en situación ventajosa, dispuestos a vencer o morir (De Agostini 1956:322). El religioso continúa relatando el ceremonial de la guerra y su valor cultural.

El simulacro de combate es otra de sus diversiones y ejercicios (Gallardo 1910: 348).

La lucha es un pasatiempo popular entre los onas (Bridges 2008: 227).

Según Chapman, si bien existían luchas reales motivadas por intereses personales o comunales, aquellas eran también un pasatiempo y un deporte y hasta guardaban un significado ceremonial (Chapman 1998:78). Dabbene (1904:72), al igual que Borgatello (1921:92), realizan una descripción de las luchas como diversión, entretenimiento o ritual entre los Selk'nam. Coiazzi (1997:62) describe el valor ceremonial y ritual de las luchas, el cuál no excluye la intencionalidad meramente bélica (Segers 1891:61).

Hasta aquí escogimos citas referidas a categorías susceptibles de encuadrar como rasgos, sin marginar el hecho de que se está hablando de sociedades ya mediatizadas por el inicio de la conquista. A la inversa, a continuación se dará espacio a aspectos atribuibles más bien a una situación claramente atravesada por el contacto, sin deslindarlos de las particularidades Selk'nam.

Respecto al temor de los Selk'nam

Como consecuencia de los maltratos recibidos de parte de los blancos, de la caza y asesinatos de los indígenas (...), demuestran gran temor cuando ven algún barco ingresar por los canales y parar en las playas habitadas por ellos; enseguida desaparecen como por encanto; es difícil ponerse en comunicación con ellos y cuando a ellos les parece que el acercamiento de los llegados es pacífico, se presentan solo los hombres y nunca las mujeres y los niños, porque varias veces estos y aquellas fueron robados por los blancos, por lo que tienen siempre la precaución de esconderlos (Borgatello 1921:74).

En la misión salesiana de Río Grande, en junio de 1895, una de las hermanas de María Auxiliadora comentaba que: llegaron muchos indios; pero acamparon a cierta distancia de la misión (...) pasamos por las chozas dando a todos galletas para poderlos contar y saber cuántos eran, pero los indios escondieron a varios de sus hijitos e hijitas (...) al cabo de un par de días los huéspedes se acercaron: hoy nos visitaron los indios, con excepción de niñas y niños, por temor -se ve-de que se los quitemos para tenerlos en casa (Crónica de las Hnas. Ma. Auxiliadora).

De citas como ésta, ligadas al devenir de la Misión La Candelaria, nos ocuparemos, como ya mencionamos, en otro trabajo.

Efectuó Serrano este viaje pacíficamente, a través de las numerosas tribus de onas, los cuáles huían cuando se acercaba; pero, vencidos su natural desconfianza y temor, pudo tratar con ellos y conocer perfectamente sus costumbres (De Agostini 1956:286).

Respecto al alejamiento de los Selk'nam a los bosques; capacidad de evasión.

En la obra de Gusinde se aprecia como los hechiceros Selk'nam eran conscientes de su impotencia ante las enfermedades ajenas a su población y cómo debían rendirse frente a tales epidemias, carentes de saber y poder (Gusinde 1982: 697, 698, 702). Era este conocimiento el que impelía a los Selk'nam a refugiarse en las zonas aledañas al lago Fagnano, dónde a su vez hallaban la tranquilidad indispensable para desarrollar su vida espiritual (idem: 682, 810).

Los aborígenes casi no se apartan hoy de los alrededores del lago Fagnano, región boscosa y montañosa (...) donde encuentran todo lo que necesitan para vivir y sobre todo lugares no frecuentados por su enemigo el hombre blanco (Gallardo 1910:119).

En la marcha, el hombre y la mujer revelan poseer mucha resistencia y la efectúan con gran celeridad (...) pero donde el ona demuestra superioridad sobre el blanco es cuando tiene que estar agachado (Gallardo 1910:114).

Por herencia, por educación y por esa continua exigencia de adaptación al medio, los onas han perfeccionado gradual y constantemente algunos de los órganos de los sentidos, siendo notables su vista y su oído; más aún, diré: que son 
admirables; y se comprende que así sea, puesto que estos dos órganos son los que más ejercitan para la conservación del individuo. Su oído es tan perfecto como la vista. Es tal el grado de educación de ese órgano, que el ona puede interpretar inmediatamente cualquiera de los sonidos que se producen en los bosques, sierras, campos o demás sitios que él frecuenta (Gallardo 1910:120-121).

Al vernos las mujeres y los niños vadearon el río, quedando los hombres en actitud defensiva, armados de arcos y flechas y parapetados tras de espesos matorrales. Al mismo tiempo incendiaban el campo para ocultarnos sus movimientos (...) numerosos eran los salvajes; pero en su mayor parte, creo, habíanse alejado del otro lado del río en protección de las mujeres y de los niños (Lista 1998:32-33)

Tienen muy agudo sentido del oído; no cabe duda de que su género de vida favorece mucho el desarrollo y perfeccionamiento de los sentidos, obligados siempre a observar los fenómenos de la naturaleza y estar continuamente alerta contra los enemigos, cuyos pasos sienten a distancias inmensas tirándose boca abajo en el suelo (Coiazzi 1997: 88-89).

los indios se vieron muy pronto obligados a ceder el terreno a los nuevos conquistadores (...) Huyendo de las persecuciones se retiraron a las regiones del sur, donde los numerosos pantanos y las tupidas florestas hacían difícil el acceso a los civilizados. (De Agostini 1956:287).

Perseguidos por los colonos que poco a poco han venido a establecerse en la Tierra del Fuego, los Onas se han retirado a los bosques y llanuras del interior, de donde salen únicamente de vez en cuando para hacer correrías con el fin de robar algunas ovejas a los usurpadores de su territorio (...) es muy difícil observarlos en las regiones adonde se han refugiado (...) siendo casi imposible sorprenderlos en sus bosques, mientras que, por el contrario, ellos saben disimular su presencia $y$ hasta acercarse a pocos pasos del enemigo sin que éste se aperciba de su presencia. Son muy hábiles en el manejo de sus armas y en la marcha, tanto en la llanura como en las montañas, son de mucha resistencia (Dabbene 1904: 68). El viajero y naturalista Roberto Dabbene, muestra en su relato varios aspectos. No sólo el robo de ganado, sino también la evasión de los aborígenes, su habilidad para esconderse y no ser descubiertos, su resistencia física y movilidad en distintos tipos de espacios.

ha aprendido hoy (1906) a desaparecer en el bosque con rapidez, tal que es fácil viajar por todo el interior de la Tierra del Fuego sin ver uno solo de estos desgraciados así se lleven las más buenas intenciones (Holmberg en Belza 1974:315)

durante los últimos años los Ona, ocultos y protegidos en los bosques de la agresión del hombre blanco, han crecido levemente en número (Furlong, 1912 en Martinic 2003: 25).

Para los primeros momentos del contacto directo en la zona sud-sudeste, -hacia 1884- Lucas Bridges relata las dificultades que en varias oportunidades tuvieron él, su padre y hermanos para poder acceder a un encuentro con los Selk'nam desde Ushuaia primero y Harberton luego. Da indicios de cómo los indígenas evitaban el encuentro y al mismo tiempo, las sensaciones que los Bridges tenían respecto de que los observaban, espiaban, estaban cerca (Bridges 2008:106, 193), y hasta proponiendo en su relato un cierto nivel de elección de los Selk'nam en cuanto a cuál debía ser el momento indicado para hacerse conocer (idem: 195).

Respecto al acercamiento de los

Selk'nam a centros civilizados

El relato de Lucas Bridges resulta una fuente de abundante información referida al avecinamiento de los Selk'nam a sus propiedades. Bien documentado se halla el hecho de cómo ya para 1907, año en que se inaugura la estancia Viamonte, era común la permanencia de los indígenas, lo mismo que su interacción con la familia. Importa aquí resaltar, en función de nuestros objetivos y de no reiterar un relato ya existente y por demás completo (Bridges 2008), como es que los Selk'nam ensayaron el contacto con los Bridges desde los primeros momentos de su instalación en Harberton. Por caso, sólo un ejemplo:

una agradable tarde de fines de 1894, aparecieron en Cambaceres dos erguidas siluetas en lo alto de una colina, a unos cuatrocientos metros de la casa (...) nos sentamos los tres y los convidé con galletas, comiendo yo también (...) pronto me rodearon como veinte indios y nos sentamos todos en círculo (...) más tarde, ese mismo día, vimos aparecer una larga y desordenada fila de mujeres 
(...) que traían también a sus hijos y a sus perros (...) y luego todos juntos se fueron a Harberton donde acamparon a la orilla del bosque, frente a nuestro establecimiento (Bridges 2008: 195-198). Para los primeros tiempos, los de Harberton, la narración indica que los Selk'nam se acercaban en familia con sus toldos y pasaban allí los inviernos o interactuaban por lapso de días y se retiraban. Ya para los años en los que se desarrolló la estancia Viamonte, se hizo habitual la escena de aquellos realizando tareas de esquila, como parte estable del establecimiento: habíamos ya construido una amplia casa- cocina, los establos, el galpón para la esquila y depósito y unas quince cómodas casitas para los onas, por si algún día se les ocurría ocuparlas (...) los onas, después de ayudarnos en el rodeo y la esquila, salían a mediados del verano a cazar en las montañas y a iniciar a los jóvenes en los misterios del Hain (Bridges 2008: 471-472).

dar cuenta que se han presentado a su comisaría (San Sebastián) unos cincuenta indígenas en la mayor indigencia, pidiendo el amparo de la Nación (...) (Carta al Ministro del Interior de la Nación Argentina, 28-6-1895 exp. 2812).

En el invierno de 1895, extremadamente duro, los indios onas de Tierra del Fuego, acosados por el frío y el hambre acudieron en el mes de julio a refugiarse en uno de los galpones de la Explotadora. El gerente dio aviso al Gobernador de estos 165 indios (...) (Aliaga Rojas, 1984:41).

los ya semi-civilizados trabajan como peones en algunas estancias o se encuentran en las misiones salesianas de Río Grande y de la isla Dawson (Dabbene 1904: 68).

Los salesianos Coiazzi (1997:89) y De Agostini (1956:292) relatan, desde la perspectiva salesiana de civilización y educación, como en la misión La Candelaria los hombres se dedicaron a la ganadería y las mujeres a los quehaceres domésticos y al trabajo de la lana y como los niños no quedaban excluidos de trabajos manuales.

Chapman menciona el caso de Angela Loij, nacida a principios de siglo, momento de mayor desconcierto por la presencia del blanco. Ya mayor, vivió alrededor de diez años en la misión salesiana La Candelaria en contacto cotidiano con ancianas Selk'nam que constantemente evocaban el pasado (...) Aunque ella hablaba el español tan bien como el Selk'nam y era católica, estaba profundamente involucrada en su cultura ancestral (Chapman 1998:18).

Según Borrero (2001:72), desde el año 1925 en adelante, la vida de los Selk'nam se desarrolló básicamente en las estancias y, finalmente, en los pueblos de El Porvenir, Río Grande y Ushuaia. Algunos se trasladaron al continente, a Punta Arenas o a Río Gallegos (...) En general estos indígenas estaban afectados a la labor de las estancias. Estas no les resultaban muy agradables a los hombres, quienes tendían a ver a dichos trabajos manuales como propios de las mujeres. Pero con el transcurrir del tiempo fueron integrándose a ese modo de vida tan diferente.

Meteten, en cambio, el hermano de Toin, había perdido todo placer en las antiguas tradiciones; a él le complacía el trabajo en las estancias (Gusinde 1982:487)

Respecto a las formas violentas de los Selk'nam

A la persecución y matanza por parte de los estancieros los indios reaccionaron defendiéndose con el arco y la flecha, más sus armas eran débiles frente a las del enemigo y bien pronto cayeron aniquilados por las balas de los blancos (De Agostini 1956: 296). Las únicas armas de que se servía el ona para la caza y la guerra eran el arco, la flechas y la honda (idem:310).

al comprender que les arrebataban sus hijos, los indios salieron de su habitual serenidad y placidez y dando gritos horribles con ademanes desesperados trataron de defender a sus criaturas (...) la madre se echaba sobre su hijo defendiéndolo con su cuerpo, mientras el padre con la expresión de todas las furias en los ojos, dando aullidos que daban pavor, se lanzaba sobre los que le robaban su niño, atacándolos con las manos, los dientes y las uñas (Aliaga Rojas 1984: 43)

El historiador chileno Mateo Martinic relata como los Selk'nam fueron respondiendo violentamente en un inicio a los ataques de los mineros o los exploradores (Martinic: 1973). Tanto L. Bridges como Belza citan acontecimientos en los que la forma violenta, aunque esporádica y coyuntural y asociada a pocas personas, no estuvo ausente en el accionar Selk'nam. Tal fue el caso de Capelo que robó armas, municiones y vestimenta a los blancos, que atacó a un grupo de mineros e inflingió dando muerte a los 
mismos, pero que justamente culminó su historia asesinado por la policía y aparentemente rechazado por sus pares a causa de su despotismo, como si Capelo se escindiera de la tradicional apacibilidad Selk'nam (Bridges 2008: 200-206). Casi un año después de estos hechos, en enero de 1896, siete indios agazapados merodeaban el corral de la caballada. Cuando tentaron el asalto se encontraron a boca de jarro con el cañón de los rifles de los peones de la estancia de la Sociedad Explotadora de Tierra del Fuego. La exposición de Belza prosigue con la secuencia de hechos que se clausura con la muerte de dos guardias y la consecuente sustracción de las armas (Belza 1974:303).

Kilkoat estaba más sediento de venganza que nunca. Al poco tiempo un grupo de mineros acampó a dieciséis kilómetros del lugar donde fue muerta su mujer; Kilkoat observaba y esperaba. Hasta que un día vio a un hombre armado con un rifle que caminaba solo a lo largo de la playa (...) Kilkoat lo dejó avanzar unos metros y lo flechó por la espalda. Luego tomó el Winchester y las municiones de su víctima y se alejó apresuradamente (Bridges 2008:264)

Las fuentes primarias también describen hechos en los que la defensa ante las persecuciones de la policía se convierte en enfrentamientos, en los cuáles los Selk'nam despliegan las habilidades propias de los grupos cazadores-recolectores en cuanto al aprovechamiento del medio como estrategia adecuada para la resistencia. También es factible plantear, según la información dada por las fuentes, la incorporación de armas de los blancos (Respuesta al Gobernador de Ushuaia, 20-3-1896 exp. 1492).

quería llevarme con ellos, pues además de haberse encariñado conmigo, como podía ocurrirle a un niño con una ardilla, pensaba que yo sería capaz de proporcionarles rifles y municiones $y$ ayudarles así a defender su tierra y vencer a sus enemigos (Bridges: 2008: 197).

los Selk'nam son un pueblo sensible, irritable y vengativo que cuida celosamente sus derechos y no deja ni una sola violación sin castigo (...) tan solo los cambios de los tres últimos decenios los obligaron a abandonar de repente sus acostumbradas luchas y venganzas contra sus compañeros de tribu, porque los poderosos blancos se interpusieron en su camino (Gusinde 1982:417)
Respecto a la apropiación de ganado

Son varios los testimonios de los administradores de estancias respecto del robo que aparentemente los aborígenes cometían. Aquí se citarán sólo algunos (Martinic 1973):

Al llegar los ganaderos en este caso y al revés del anterior fue el indígena el agresor al apropiarse, o intentar hacerlo, de ovejas de la hacienda, lo que obligó a la adopción de medidas de defensa que a su tiempo generaron combates desesperados.

Mauricio Braun escribía una carta el 30 de agosto de 1894 en la que expresaba efectivamente los indios nos han molestado bastante pero no nos han robado todavía tantas ovejas como se dice; en estos momentos convenía exagerar las cosas para que el Gobierno tomara algunas medidas pero en realidad hasta hoy no hemos perdido más de cien ovejas durante todo el tiempo con los indios

A su vez, Martinic adjunta la siguiente información para contrastar con los datos brindados por el terrateniente en su carta:

el directorio de la Explotadora en su presentación al Presidente de la República expresaba a propósito de pérdidas que los indios ya habían robado 20.000 ovejas y destruido millas y millas de cercos de alambres. (...) Las pérdidas de ovejas tanto por robo como por deterioro a manos de los indígenas no llegaron a 2.000 cabezas en el lapso comprendido entre 1894 y 1900.

Estimamos que un individuo sorprendido en el acto de robar es un ladrón y como tal debe ser sometido a la acción de la justicia, cuanto además que las autoridades constituidas nos han autorizado para tomar esas medidas.

nuestra situación ha llegado a hacerse sumamente difícil e insostenible si no se toman medidas rápidas para amparar nuestras haciendas de los ataques diarios de los indígenas.

las 600 ovejas malvineras con las que se inició la dotación, ninguna quedaría al poco tiempo, según recordaría años después don Rodolfo Stubenrauch, pues los indígenas dieron rápida cuenta de ellas (referencia a la primer estancia fueguina instalada en 1885 sobre la costa de la Bahía Gente Grande).

Los ataques de los indios a las caballadas del pueblo, llenaba de temor a la población que 
reclamó la presencia de policías para tranquilizar a la comunidad que clamaba resguardo para sus vidas y bienes.

destruyen los alambrados y los cercos (...) destruyen e inutilizan, a veces, hasta quinientas y mil ovejas (Migone 1935: 114) (...) Indios rebeldes, que merodeaban en las cercanías, aprovechando la circunstancia crítica en la que se hallaban los misioneros, hicieron irrupción sobre las 59 cabezas de ganado que aun quedaban, dejando a los sobrevivientes en la mayor privación (idem, 133).

Estos mismos indios hace algunas semanas robaron en el establecimiento, un buen número de animales y destruyeron por mero gusto dos millas del alambrado (Respuesta al Gobernador de Ushuaia, 20-3-1896 exp. 1492).

Que persiguiendo a unos indios ladrones que se tenía conocimiento habían invadido el establecimiento Primera Argentina del Señor José Menéndez en el Departamento de Río Grande, se les alcanzó por la policía que mandaba mi persona el jefe de la misma, quitándole trescientas ovejas que arreaban. Para restituir dicha hacienda hubo que sostener combate con ellos del cual resultó un indio muerto y herido de flecha, de gravedad., el jefe mencionado, el señor Mc Lennan mayordomo del Señor Menéndez (...) en ese encuentro que tuvo lugar el día 17 de febrero ppdo. se pudieron tomar prisioneros después de una resistencia tenaz cinco indios de pelea, cuatro mujeres y dos criaturas, los que serán remitidos al Señor Juez letrado del Chubut por el primer transporte con el sumario correspondiente (AGN, carta al Ministerio del Interior, 26-3-1897. exp. 1385). En este fragmento se puede apreciar no sólo la apropiación de ganado a la estancia Primera Argentina apenas instalada, sino también la connivencia entre autoridades y propietarios. Pero es conveniente remarcar el hecho de que los aborígenes fueron remitidos a Chubut. Dicha disposición estaba contemplada en el marco legal vigente para la época y constituía una de las herramientas concretas elaboradas por el estado argentino para resolver el problema del indio. Otros documentos despachados desde la Gobernación de Ushuaia al Ministerio del Interior dan cuenta de que este procedimiento era la propuesta de la autoridades nacionales ante las constantes y numerosas peticiones por parte de sus pares locales, las que en definitiva debían resolver las contradicciones de la colonización, en relación con la permanencia de los aborígenes en su lugar, sea como tales, sea como ciudadanos (AGN, carta al Ministro del Interior, 4-8-1897. exp. 2900). La improvisación, lo mismo que los reclamos de insumos y dinero por parte de los gobernadores eran moneda corriente, proponiendo incluso la formación de una colonia en el continente, donde poder trasladar a los aborígenes fueguinos (AGN, cartas al Ministro del Interior, 4-8-1897. exp. 2900; 20-7-1897. exp. 2920; 28-61895 exp. 2812; 21-3-1896 exp. 1492). Insistimos en puntualizar este dispositivo de poder -traslado a Chubut- de momento que no ha sido enfatizado por la historiografía argentina, aunque si es una de las citas de la obra de Belza (1974: 324).

Se ha dispuesto que el Gefe de Policía, con varios gendarmes, salga para aquellos puntos (Puerto Harberton, Bahía Moat) (...) con objeto de efectuar una expedición e impedir que los indígenas cometan actos de pillería en los varios establecimientos ganaderos allí instalados (AGN, carta al Ministro del Interior, 24-11-1897. exp.4670). Consentimos que por el tipo de accionar, este documento hace referencia a grupos Selk'nam.

\section{A MODO DE SÍNTESIS Y CONCLUSIÓN}

El odio de los indígenas contra el blanco no es infundado, irreflexivo. No se olviden jamás las espantosas atrocidades que tantos europeos cometieron impunemente contra aquel pueblo indefenso! Quien sopesa desprejuiciadamente los hechos, tal vez se asombre por la actitud pasiva de los actuales aborígenes, que, con estoica resignación, soportan tantas injusticias y tanto dolor, a pesar de que la sed de venganza llega a veces hasta el desborde. Ante su propia conciencia, el indígena justifica su lucha contra el blanco con referencias al derecho de defensa propia, a la falta de alimentos, al derecho de venganza (Gusinde, 1982:509)

La cita de Gusinde que principia este apartado es más que elocuente. Oficia de síntesis de las tantas potenciales sensaciones que pudieron haber transitado la mentalidad Selk'nam, a partir del contacto con el cristiano/civilizado: conciencia e impotencia, odio y resignación, venganza e indefensión.

¿Los Selk'nam resistieron finalmente? ¿Cuánto quisieron y cuánto pudieron? ¿Tiene sentido incor- 
porar acepciones como eficiencia o eficacia? ¿Cuál es el límite de resistir, si hacerlo pasivamente podría incluir el suicidio, el aborto o el infanticidio, tal como se propusiera para otras regiones? (Roulet 1993). ¿Es plausible trazar sólo un escenario de meras respuestas? Sugerimos la idea, al menos para instar la reflexión, de que resistir es estimable en sí mismo, es sinónimo de existencia, presencia, conciencia de los hechos, de autovaloración y voluntarismo, por ende de intentos de elección y acción. Si se atiende al marco teórico escogido, se apreciará que no nos adecuamos a la idea de que resistir sea sólo adaptarse y re-accionar, como se preguntara la historia hace ya algunos años (Nofri 1998). Claro que procurar un análisis sin determinismos no debería homologarse con la ausencia de los mismos arribada la hora de observar los resultados del proceso histórico.

A partir de una primer lectura de las fuentes, algunas primarias, otras etnográficas o secundarias, el caso Selk'nam podría encuadrarse en una realidad en la que las condiciones impuestas determinaron la estrategia de resistencia y dejaron escaso margen de operación al segundo plano dialéctico. Los relatos parecieran proponer que los Selk'nam no incurrieron en la estructuración de una confrontación abierta con la sociedad blanca. Con el correr de los años, el grado de conciencia de su situación, lo mismo que su capacidad de esgrimir resistencia de algún tipo, habría fluctuado, aunque allende las capacidades y alternativas en cada lapso, los Selk'nam parecieran haberse mostrado relativamente pasivos ante las tácticas de la civilización. Ocurre que la eficacia de las relaciones de dominación gestadas y las peculiaridades de la racionalidad impuesta ratifican el carácter asimétrico de las conexiones entre indígenas y blancos y su funcionalidad llegada la hora de anular algún tipo de manifestación de insubordinación.

Como sociedad cazadora recolectora, los Selk'nam habrían limitado su accionar a refugiarse en las zonas alejadas de las estancias, aquellas aledañas al lago Fagnano, donde a su vez hallaban la tranquilidad indispensable para desarrollar su vida espiritual. Tanto Borrero (2001:80) como Martinic (2003), aluden a esta situación, como estrategia consciente aunque infructuosa, como única alternativa al cercado de los territorios, respectivamente. Según Borrero, la respuesta inicial de los Selk'nam ante la colonización sedentaria fue incentivar una estrategia de evitar el contacto, que ya debían estar utilizando desde los tiempos de los primeros encuentros (...) la estrategia utilizada por los Selk'nam ya había sido puesta a prueba en otros lugares del mundo obteniéndose como resultado sólo ganar tiempo, demorar el desenlace final (Borrero 2001:80). Una variante de dicha estrategia habría sido retirarse hacia el sur en verano, convivir con los Yámana y hasta trabajar en la estancia Harberton (cercana a Ushuaia) para retornar a los bosques en invierno, cuando la presencia blanca disminuía debido a la crudeza del clima (idem: 94).

Quisiéramos aquí reforzar este esquema, aunque introduciendo cierto matiz cronológico, ya que tal vez no resulte del todo conveniente aseverar que el alejamiento de los Selk'nam constituyó la respuesta inicial exactamente. De la lectura de las citas propuestas, podría diseñarse una periodización alternativa de la resistencia, si bien ésta se dio en todo momento, variando su forma, la cual no era excluyente ni absoluta -y esto último es muy importante de remarcar-. Básicamente podría decirse que durante los primeros años, los Selk'nam resistieron a través del contacto: ensayaron acercarse a la misión salesiana en Río Grande, a las estancias y a las comisarías.

En dicha situación resistieron destruyendo alambrados, apropiándose de ovejas, reaccionando violentamente a las actitudes que su presencia generaba en los representantes de la sociedad blanca, ostentando temor. Este aspecto será desarrollado en el trabajo citado sobre la misión La Candelaria, lugar en el que se sucedieron variadas formas de resistencia. Es decir, más allá del grado de conciencia que pudieran tener de las secuelas del enfrentamiento, los Selk'nam optaron -tómese con moderación la carga concluyente- por resistir a través del contacto. Existen diversos trabajos (Martinic 1973, 1982, 1990, 2003; Borrero 2001; Aliaga Rojas 1984; Bridges 2008; Belza 1974; entre otros) que sin adoptar formas analíticas específicas (resistencia), presentan contenidos útiles para fundamentar las tesis aquí volcadas, a partir de la descripción de los hechos que entre 1885 y 1900 marcaron lo abrupto de la conquista: deportaciones, matanzas, persecuciones, enfrentamientos. La razón de invocar formas laxas es porque los Selk'nam también eludieron a los blancos durante los primeros años, por caso para la región sud-sudeste del sector argentino para el 
período 1884-1890, según los testimonios de L. Bridges.

En una etapa posterior, hacia 1900, los Selk'nam habían ya disminuido considerablemente su número -se había dado la hecatombe étnica de 1890-1900 (Martinic 2003) y la resistencia tomaría forma de evasión, de refugio en zonas alejadas. La contraparte podría hallarse en aquellos aborígenes que se incorporaron a las estancias o a la institución religiosa. Una vez más el historiador chileno, ofrece ejemplos factuales (Martinic 2003), iniciando su relato con la siguiente expresión: al concluir hacia 1900 la persecución a los selk'nam en el territorio fueguino chileno por parte de las compañías colonizadoras (con muertes y deportaciones) se tuvo por extinguida virtualmente la población indígena, al punto de cesar toda referencia a los mismos en las publicaciones de la época que se ocuparon de la etnografía fueguina.

Más aún, el propio Borrero indica cómo las matanzas sistemáticas duraron poco tiempo, pero produjeron un efecto devastador (Borrero 2001:120) o cómo en el año 1887 los indígenas destruyeron alambrados y continuaron cazando ovejas y este fue un patrón que continuó al menos durante tres años (idem: 65).

Los Selk'nam, no habrían contado con la opción -no sabemos si con la intención- de elaborar un movimiento social reformista, revolucionario o mesiánico o de gestar una nueva etnia. Tampoco ocurrió como en las regiones de pampa y nord patagonia, dónde los indígenas generaron estrategias económicas y políticas que posibilitaron el control del territorio y de los recursos que circulaban; fueron parte del sistema y asistieron a cambios profundos en el interior de sus comunidades en el transcurso del proceso de contacto interétnico que duró más de doscientos años. Dónde se consolidaron jefaturas que recurrieron alternativamente a fusiones $y$ fisiones entre comunidades, (...) entre unidades sociales que establecían alianzas y las rompían de acuerdo a específicos intereses coyunturales (Correa 2002). Dónde la guerra fue una estrategia de resistencia, una instancia económica y política que permitía la negociación. Este no fue el caso de los Selk'nam, comunidad que en menos de cuarenta años ya había sido asolada.

Los Selk'nam conocían sólo la guerra entre pares, entre grupos que funcionaban de igual mo- do, dónde las razones y los métodos no sólo eran corrientes, sino que por demás simples; dónde, circunstancialmente, la lucha esfumaba sus fronteras con la actividad lúdica, ritual o con rasgos ceremoniales. Personalidades sobresalientes, encarnadas en figuras como Capelo o Cauchicol, expresaron su conciencia de los hechos atacando, robando armas, huyendo, propiciando un comportamiento más bien vengativo. Eran dóciles, buenos, alegres, serviciales e inspiraban confianza -según el tamiz de sus observadores- y una de sus reacciones fundamentales fue el temor, manifestado en el ocultamiento de mujeres y niños, en el decir que sí, en el alejarse. Una sociedad carente de jerarquías potencialmente explotables para la elaboración de estrategias político-económicas de negociación y que tampoco instó su construcción a partir del contacto, a fin de generar una oportunidad que redundara en resistencia, participación en el sistema o, más complejo aún, en etnogénesis, como sucediera para el caso reche-mapuche.

El eje parecía ser lo espiritual. Tanto Chapman como Gusinde enfatizan la complejidad y la importancia de este aspecto, el valor otorgado y la relevancia del mismo en la organización del pueblo Selk'nam. De hecho, las divisiones sociales planteadas por Fiore (2006) estrechan lazos con facetas culturales. Chapman y Gusinde imprimen en la exclusiva conversión externa de los aborígenes al catolicismo, una forma de resistencia. La subjetividad, las estructuras cognitivas pudieron haber operado como obstáculos para la construcción de un Estado sustentado en principios civilizatorios ávidos de homogeneizar para dominar (Correa com. pers.). La resistencia cultural de los Selk'nam puede apreciarse también en las fotografías, ya que puestos en un plano comparativo con Yámanas y Alacaluf, serían quienes habrían conservado una más marcada tendencia a exponer sus ropas y artefactos tradicionales. Quienes habrían elegido, en plena fase de transculturación en las sociedades fueguinas, remitirse a su cultura (Fiore y Varela 2007).

Por momentos, el escrutinio de las fuentes avecina al lector a imágenes de sometimiento, como si los Selk'nam hubieran consentido las instituciones productivas y religiosas: fueron mano de obra y aprendices de civilización y de alguna manera legitimaron la superioridad del discurso y el accionar dominantes. Empero, se dificulta admitir que los 
aborígenes labraron una ideología de la sumisión cuando el contexto devino determinante. Los dispositivos de poder fueron eficaces. El tiempo y las formas en las que ocurrió el contacto, igual que el tipo de sociedad conquistada, fueron factores significativos. La desestructuración de los Selk'nam responde en parte a la severidad de las circunstancias espacio temporales en las cuáles debieron afrontar el contacto (Casali et. al.2006.). Si interconectamos el aspecto geográfico insularidad, con la clave de la agencia conquistadora desterritorialización y su par de la agencia del conquistado movilidad, se deriva el desenlace.

El tipo de sociedad, en conjugación con el tipo de dispositivos de poder aplicados, contrajeron el tiempo, el espacio y las posibilidades fehacientes de proyectar una estrategia. En palabras de Néspolo -aunque ocurriendo lo contrario a lo planteado en su caso de estudio-, los Selk'nam se encuentran condicionados a una lógica o a un imperativo de adaptación (Néspolo 2007:5). Crucial fueron factores -que como vimos algunos autores incluyen en el accionar estatal- tales como las enfermedades y alteraciones en el medio y sus consecuencias biológicas y culturales.

Pero, la sociedad Selk'nam fue parte de un vínculo dialéctico y como tal modificó a su extremo opuesto. Compuso un complejo escenario como respuesta, no indefectiblemente pasivo. Ensayaron contactarse con los religiosos y eligieron no permanecer durante los primeros tiempos, rompieron alambrados, se apropiaron de ganado, robaron armas, se resistieron violentamente a los ataques homólogos y a los intentos de deportación, pero ocurría una forma defensiva o vengativa y coyuntural, acorde al estímulo recibido (por ejemplo, el asesinato de algún pariente o el intento de detención por parte de las autoridades) y a las circunstancias en las que debían operar. También canalizaron su rebeldía potenciando los enfrentamientos intraétnicos, irremediablemente, lo cuál potenció su situación de debilidad ante el invasor: otras desventajas eran su falta absoluta de disciplina y el hecho de estar divididos en pequeños clanes que continuamente peleaban entre sí (Bridges 2008: 260).

Se alejaron de las estancias y de la Misión Salesiana de Río Grande para retirarse a los bosques o -lo contrario- se acercaron para refugiarse en las primeras como mano de obra y en la segunda como discípulos de religión, pero también como trabajadores. Por otra parte, la complejidad de la realidad Selk'nam y sus actitudes, visibles en las fuentes para el caso de la misión salesiana La Candelaria, descubre más que certezas de inteligencia y perspicacia (Casali y Guichón 2008, MS).

Los Selk'nam estaban ahí cuando llegaron los empresarios ganaderos y siguieron estando mientras pudieron. Resistieron coyuntural e individualmente, aunque también en grupo. Procuraron mantener latente sus creencias y su cultura, sus rituales y prácticas de socialización. Impelieron al poder estatal y privado a organizar un sistema de policía y control. Las empresas ganaderas se vieron impulsadas a estructurar técnicas de acercamiento a los indígenas que no tenían previstas y que no solamente se correspondían con las armas: cercaron los territorios, instalaron puestos de vigilancia permanente y hasta debieron invocar el concurso del reverendo Thomas Bridges, cuyo ascendente sobre los aborígenes era conocido (Martinic 1973:19).

Claro que A modificó a B y B afectó a A. Aunque no es fácil rehuir a la impresión de que ciertos resultados parecieran dar por tierra con las ecuaciones. Los Selk'nam sintieron odio y ganas de matar. Se intentó discutir aquí acerca de cuanto hubo de voluntad y elección y cuanto de resignación y acomodo. Una vez más, Gusinde ofrece potenciales respuestas.

A causa del cambio de la situación en los últimos decenios, no faltaron intentos de ultimar también a los europeos, basándose para ello en las costumbres propias de aquellos hechiceros. (...) En la lucha abierta, los nativos habían empleado todo su valor para defenderse de los europeos. También los xon, en especial, habían puesto en juego sus fuerzas de actuación invisibles; pero todos los esfuerzos fueron completamente en vano, a pesar de que en sus actos mágicos los guiaba y los fortalecía la ira más terrible y la fuerza que otorga la defensa propia desesperada. Una noche, Tenenesk me comentó con mucho detalle las luchas sostenidas por los blancos contra sus coterráneos. Repentinamente, sus agudos ojos adquirieron brillo, comenzó a temblar fuertemente a causa de su excitación, y lo que dijo parecía el grito de un desesperado: ¡Oh, si nosotros, los xon, hubiéramos podido atrapar con nuestro yauatejn el kaspi de los koliot! ¡A todos esos odiados blancos 
los hubiéramos matado! En aquel entonces aun había muchos y muy poderosos xon. Cada uno de ellos trató con el mayor esfuerzo de acercarse a1 kaspi de los blancos, pero ninguno tuvo éxito. ¡Cuantas veces lo intenté yo mismo! No se decir otra cosa: El kaspi de los blancos es distinto del kaspi de nuestros selk'nam. El kaspi de ellos es tan móvil, tan salvaje e indómito, que siempre se le escapa a nuestros yauatejn. De no ser así, nosotros los xon hubiéramos dado rápidamente el golpe de gracia a esos extraños (...) la fuerza de los hechiceros no puede atentar contra la vida y el alma de los blancos (Gusinde, 1982: 698).

\section{AGRADECIMIENTOS}

Al Dr. Ricardo A. Guichón por la lectura del manuscrito y su permanente apoyo a mi tarea. Al Dr. Martín H. Fugassa y a la Prof. Analía Correa por la lectura del texto y por sus valiosos aportes. A Carla Betanzo, encargada del archivo del Museo del Fin del Mundo, por su generosidad y su entusiasmo por la historia. A la Lic. Florencia Carlón por facilitarme bibliografía, siendo yo única responsable de las opiniones y conceptos vertidos en el presente artículo. Este trabajo fue posible gracias al financiamiento generado por los proyectos FONCyT PICT- 13889 y PICT 01520.

\section{FUENTES DE CONSULTA}

\section{Primarias}

Archivo Museo del Fin del Mundo

-Cartas al Ministro del Interior de la Nación Argentina: 28-6-1895 (exp. 2812); 21-3-1896 (exp. 1492); 26-31897 (exp. 1385); 20-7-1897 (exp. 2920); 4-8-1897 (exp. 2900); 24-11-1897 (exp. 4670); 14-12-1897 (exp. 4842).

-Respuestas al Gobernador de Ushuaia: 20-3-1896 (exp. 1492); 20-8-1897 (exp. 471).

-Carta al Jefe de Policía Ramón Cortés del Comisario José Pezzoli, Río Grande, 25-1-1896.

Etnográficas y etnohistóricas

BEAUVOIR, J. 1915. Los Selk'nam, indígenas de la Tierra del Fuego. Sus tradiciones, costumbres y lengua. Librería del Colegio Pio IX. Buenos Aires.
BORGATElLO, M. 1921. Nozze D'argento. Ossia 25 anni di missione salesiana nella Patagonia meridionale e Terra del Fuoco, della prefettura apostólica di Mons. G. Fagnano (1887-1912). Societá editrice internazionale. Torino.

BRIDGES, T. 1886. El confín sur de la república. La Tierra del Fuego y sus habitantes. Boletín del Instituto Geográfico argentino 7: 200-212. Buenos Aires.

BRIDGES, L. 2008. El último confín de la tierra. Sudamericana. Buenos Aires.

CHAPMAN, A. 1998. Los Selk'nam. La vida de los onas. Emecé. Buenos Aires.

COIAZZI, A. 1997. Los indios del Archipiélago fueguino. Ateli. Punta Arenas.

DABBENE, R. 1904. Viaje a Tierra del Fuego y a la isla de los Estados. Boletín del Instituto Geográfico argentino. 21:3-78

DE AGOSTINI, A. 1956. Treinta años en Tierra del Fuego. Peuser. Buenos Aires.

GAllaRDO, C. R. 1910. Los onas. Cabaut y Cía. Buenos Aires.

GUSINDE, M. 1951. Hombres primitivos en la Tierra del Fuego (de investigador a compañero de tribu). Escuela de Estudios hispano-americanos de Sevilla. Sevilla.

GUSINDE, M. 1982. Los Indios de Tierra del Fuego. 1(1) Centro Argentino de Etnología Americana. Buenos Aires.

LISTA, R. 1998. Viaje al país de los Onas. Tierra del Fuego. Buenos Aires. Establecimiento Tipográfico de Alberto Núñez.

MASSA, L. 1945. Monografía de Magallanes. Setenta años de acción salesiana en el sur 1886-1946. Escuela Topográfica del Instituto Don Bosco. Punta Arenas.

MIGONE, M. 1935. Un héroe de la Patagonia. Librería del Colegio Pío IX. Buenos Aires.

SEGERS, P. 1891. Hábitos y costumbres de los indios onas. Boletín del Instituto Geográfico Argentino. Tomo XII. (Mayo-junio): 56-82.

\section{BIBLIOGRAFÍA}

ALIAGA ROJAS, F. 1984. La Misión en la isla Dawson (18891911). Anales de la Facultad de Teología. XXXII (2). Universidad Católica. Santiago de Chile.

BANDIERI, S. 2005. Historia de la Patagonia. Sudamericana. Buenos Aires.

BECHIS, M. 2005. La interacción retroalimentadora o dialéctica como unidad de análisis de la Etnohistoria, un campo antidisciplinario del saber. Actas del VI Congreso Internacional de Etnohistoria. Buenos Aires. 
BELZA, J. E. 1974. En la isla del fuego $1^{\circ}$ Encuentros. Instituto de Investigaciones históricas de Tierra del Fuego. Buenos Aires.

BELZA, J. E. 1975. En la isla del Fuego 2ํolonización. Instituto de Investigaciones históricas de Tierra del Fuego. Buenos Aires.

BOCCARA, G. 2001. Mundos Nuevos en las fronteras del Nuevo Mundo. Nuevo Mundo Mundos Nuevos 1. Edición electrónica.

BOCCARA, G. 1996. Notas acerca de los dispositivos de poder en la sociedad colonial-fronteriza, la resistencia y la transculturación de los Reche-Mapuche del Centrosur de Chile (XVI-VIII). Revista de Indias. LVI(208): 659-695. Madrid.

BORRERO, L. 2001. Los Selk'nam (Onas). Galerna. Buenos Aires.

BRAUN MENÉNDEZ, M. 1939. Pequeña historia fueguina. Emecé.Buenos Aires.

CASALI, R., M.H. FUGASSA y R.A. GUICHÓN. 2006. Aproximación epidemiológica al proceso de contacto interétnico en el norte de Tierra del Fuego. Magallania. 34 (1): 141-155. Edición electrónica.

CASALI, R. y R. A. GUICHÓN. 2008. Contacto interétnico en el norte de Tierra de Fuego: estrategias de resistencia Selk'nam en la misión salesiana La Candelaria. MS.

CARDOSO DE OLIVEIRA, R. 1988. Articulación interétnica en Brasil. Procesos de articulación social. Hermitte y Bartolomé (compiladores). Amorrortu. Buenos Aires.

CORREA, A 2002. Jefaturas indias e integración económica en el sur bonaerense (primeras décadas del siglo XIX). Cuadernos del Sur. Historia 30-31.

CORREA, A. 2004. Relaciones de dominación estatal y desestructuración de los pueblos indígenas pampeanos (18101829). Informe final Beca de Investigación: Formación Superior. UNMdP. Mar del Plata.

FIORE, D. 2006. La manipulación de pinturas corporales como factor de división social en los pueblos Selk'nam y yámana (Tierra del Fuego). Estudios Atacameños 31: 129-142. Edición electrónica.
FIORE D. y M.L. VARELA. 2007. Excavando Fotos. Arqueología de la cultura material y las prácticas sociales de los pueblos fueguinos. En: Fueguinos. Fotografías Siglos XIX y XX. Imágenes e Imaginarios del Fin del Mundo. M. Alvarado; C. Odone; F. Maturana; D. Fiore (eds.). Pehuen. Santiago de Chile.

GARCIA MORO, C. 1992. Reconstrucción del proceso de extinción de los Selk'nam a través de los libros misionales. Anales del Instituto de la Patagonia 21: 33-46. Punta Arenas.

MASSONE, M., D. JACKSON y A. PRIETO. 1993. Perspectiva arqueológica de los Selk'nam. Centro de Investigaciones Diego Barros Arana. Santiago de Chile.

MASSONE, M. 1987. Los cazadores paleoindios de Tres Arroyos (Tierra del Fuego). Anales del Instituto de la Patagonia 17: 47-60. Punta Arenas.

MARTINIC, M. 1973. Panorama de la colonización en Tierra del Fuego entre 1881-1900. Anales del Instituto de la Patagonia 4: 5-69. Punta Arenas.

MARTINIC, M. 1982. La tierra de los fuegos. Municipalidad de Porvenir. Magallanes.

MARTINIC, M. 1990. El genocidio Selk'nam: nuevos antecedentes. Anales del Instituto de la Patagonia, 19: 23-28. Punta Arenas.

MARTINIC, M. 2003. Los últimos Selk'nam en Tierra del Fuego chilena. Magallania. 31: 21-31. Punta Arenas.

NÉSPOLO, E.A. 2007. Las misiones jesuíticas bonaerenses del siglo XVIII, ¿una estrategia político-económica indígena?. Tefros. 5 (1).

NOFRI, M.C. 1998. La elaboración de estrategias de resistencia-permanencia de los indígenas ranqueles frente al establecimiento de las misiones franciscanas como mecanismos de dominación (1868-1880). XII Jornadas de investigación de la facultad de Ciencias Humanas, UNLPam. Santa Rosa.

RATTO, S. 2007. Introducción. Mundo Agrario. Revista de estudios rurales. 15 (2). Edición electrónica.

ROULET, F. 1993. La resistencia de los guaraní del Paraguay a la conquista española (1537-1556). Editorial Universitaria Universidad Nacional de Misiones. Posadas. 
